\title{
Leadership and nurses' satisfaction with supervision
}

\author{
Rosa C.C.P. Melo ${ }^{* 1}$, Diogo S. Neves ${ }^{2}$ \\ ${ }^{1}$ Nursing School of Coimbra, Coimbra, Portugal \\ ${ }^{2}$ LVM, Physical Rehabilitation Centre - Rovisco Pais, Tocha, Portugal
}

Received: July 30, 2014

DOI: $10.5430 /$ jha.v4n4p57

\author{
Accepted: April 10, 2015 \\ Online Published: May 14, 2015 \\ URL: http://dx.doi.org/10.5430/jha.v4n4p57
}

\begin{abstract}
Objective: The main objectives of this study were to evaluate the performance of leadership roles and the nurses' satisfaction with supervision and to examine the relationship between the performance of leadership roles and nurse satisfaction.

Methods: A quantitative, descriptive, correlational and transversal study was conducted, with a sample made up of 79 nurses practicing in two public health institutions in the district of Coimbra in Portugal. Data collected included demographic characteristics, eight leadership roles and five levels of supervision satisfaction. The Munson's Supervision Satisfaction Scale and the Quinn's Leadership Scale were used. The instruments adaptation and validation study revealed adequate psychometric properties being considered as valid instruments for the quantitative study pursuance.

Results: The results indicate an acknowledgement of all roles of leadership, having a tendency towards the roles of producer (4.73) and director (4.64) indicating leadership centered on the rational goals model, revealing a greater concern with efficiency and productivity. The role of innovator was the one least perceived (4.16). Most nurses (83.50\%) were satisfied with the supervision. The relationships between all the leadership roles and nurse satisfaction were positive, with the roles of facilitator $(r=.842$; $p<.001)$ and mentor $(r=.871 ; p<.001)$ with the strongest correlation.

Conclusions: The investigation revealed that the leader who plays all roles of leadership raises the level of supervision satisfaction of the nurses he/she leads. A poor performance of the facilitator role suggests the need for head nurses to acquire leadership skills which help them manage interpersonal conflicts and promote cohesion and teamwork within the current context of health care restructuring and decreased nurse staffing levels.
\end{abstract}

Key Words: Nursing, Leadership, Leadership roles, Supervision satisfaction

\section{INTRODUCTION}

Managers' capabilities, attitudes and aptitudes to influence their collaborators' behavior, in order to achieve their objectives, are of an extreme importance in any health organization. Similarly, hospitals' management faces challenges due to their environment which is in constant transformation, making it also necessary to have competent managers in the leadership process of their teams. ${ }^{[1,2]}$

Leadership is one of the modern age's major concerns, because it originates, to a large extent, the efficiency and ef- fectiveness of groups and organizations. ${ }^{[3]}$ So, the head nurse presents himself/herself as a key element in the nursing teams' dynamics, as a decisive leader in the effective functioning of the organization. ${ }^{[4]}$ The leadership process occurs in both directions, as the influence generated is directed both from the leader to the subordinates as well as from the subordinates to the leader, although the former is fairly superior. ${ }^{[5,6]}$ For effective leadership there must be a symbiotic relationship between the head nurse and his/her nurses to promote the strengthening of the team, transmitting

*Correspondence: Rosa C.C.P. Melo; Email: rosamelo@esenfc.pt; Address: Coimbra Rua da Fonte nº 12, 3020-272, Coimbra, Portugal. 
power to the team, enhancing the value of personal skills and making sure that each element acknowledges the purpose and meaning of their work. ${ }^{[7]}$

For the maintenance and expansion of this relationship, it is important that staff nurses are satisfied with the leadership of its head nurse, as the most significant determinant of job satisfaction is the positive relationship with superiors. Thus, it becomes necessary to understand in what way the superiors' leadership behavior influences the satisfaction of the subordinates, in order to help them develop behaviors and create a working environment that favors the employees' needs. ${ }^{[7]}$

In this context, we raise the question: Does the head nurse's performance in leadership roles contribute to the staff nurses' satisfaction with nurse supervision?

Because few studies have investigated the relationships between nurse satisfaction and specific leadership roles, our study aimed to: (1) evaluate the nurses' perception about the head nurse's performance in leadership roles, (2) identify the level of satisfaction with nurse supervision, (3) examine the relationships of nurse satisfaction with each of leadership roles, and (4) identify other factors influential to nurse satisfaction with supervision.

\subsection{Conceptual framework}

Leadership has been creating a growing interest among the scientific community, not only for its complexity but also because it enables the success of organizations. ${ }^{[2]}$

Over the years, research on leadership allowed the development of various theories. Leadership theories have evolved from a behavioral approach to transactional and transformational approach. Quinn \& Rohrbaugh are of the opinion that the leader who combines transactional leadership and transformational leadership gets higher performance levels. ${ }^{[8]}$ This study was based on Quinn \& Rohrbaugh's ${ }^{[9]}$ spatial model of organizational effectiveness analysis, which has been considered one of the 40 most important models in the history of management and largely used in organizational research for over 25 years. ${ }^{[10,11]}$ The model consists of four quadrants, which arise from the overlapping of two representative axes of two key dimensions for the conceptualization of organizational efficiency, flexibility versus control (vertical axis), and the internal orientation versus external orientation (horizontal axis) ${ }^{[9]}$ (see Figure 1).

Quinn's model of leadership is based on the Competing Values Framework for organizational analysis and consists of four models of leadership: the human relations model, open systems model, internal processes model and rational goals model. The human relations model is represented by the roles of mentor and facilitator; the open systems model is represented by the roles of broker and innovator; the internal processes model is represented by the roles of monitor and coordinator, and the rational goal model is represented by the roles of producer and director (see Figure 2).

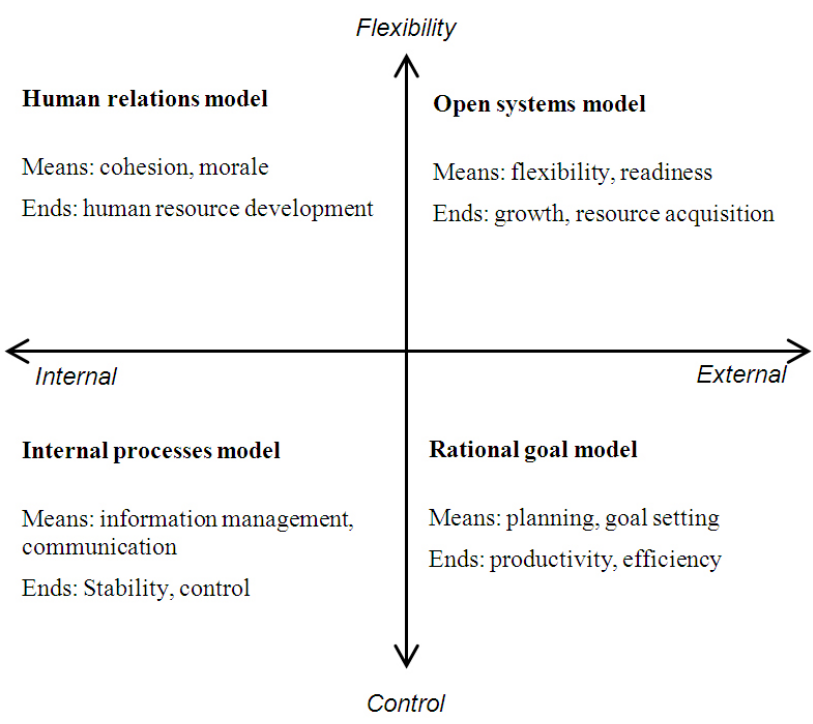

Figure 1. Spatial model of organizational effectiveness analysis - Competing Values Framework: organizational effectiveness

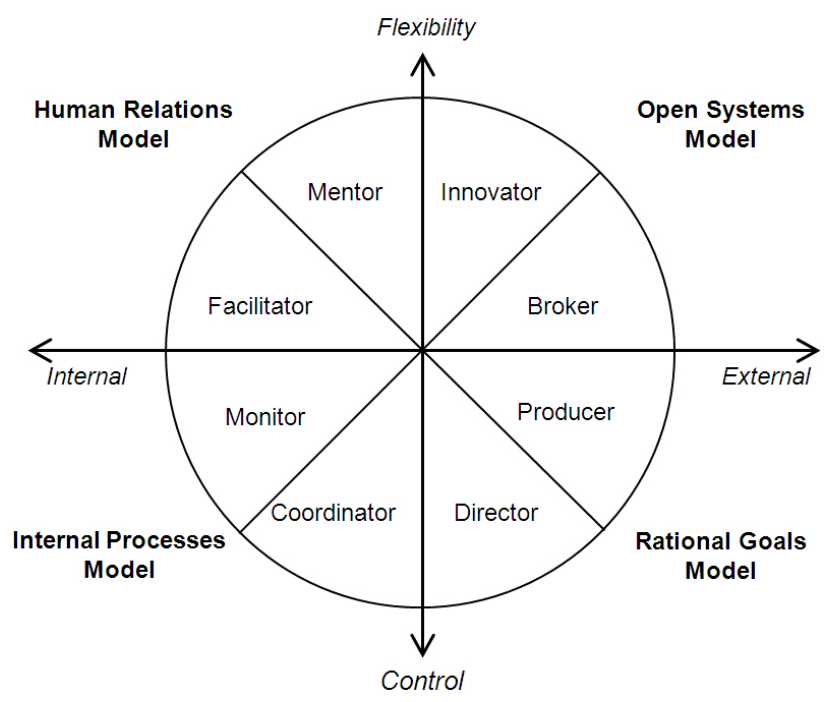

Figure 2. Competing Values Framework: leadership roles

The human relations model, which includes the roles of facilitator and mentor, gives emphasis to commitment, cohesion and morale. The premise is that involvement results in commitment and the core values are participation, conflict resolution, and consensus building. The role of the manager is to become an empathic mentor and a process-focused 
facilitator. According to these authors, ${ }^{[9,12]}$ facilitators encourage collective efforts, promote cohesion and team work, and manage personal conflicts. Mentors dedicate themselves to developing people through careful guidance and empathy. In this role, the manager contributes to enhancing skills and planning the individual development of the subordinates.

From these authors' point of view, ${ }^{[9,12]}$ the open systems model results from the need for leadership in a rapidly changing world where knowledge is vast. On one hand, leaders have little time to devote to organization and planning issues and, on the other hand, they are forced to make quick decisions. Therefore, the key processes are adaptation, creative problem-solving, innovation, and management change. Thus, according to these authors, ${ }^{[9,12]}$ the manager should become a creative innovator and a negotiator who uses his/her power to have an influence within the organization. Innovators are usually visionaries who facilitate adaptation and change, while negotiators are concerned with sustaining external legitimacy and obtaining external resources. For this reason, they should have the power and ability to persuade and influence others.

The rational goal model aims at productivity and profit. Thus, from this perspective, the role of the manager is to become a deciding director and a pragmatic producer. As directors, managers give emphasis to planning, the establishment of goals and the definition of objectives. In turn, producers are task-oriented, keep focus on work and show high interest and personal motivation. ${ }^{[9,12]}$

In the internal processes model, the effectiveness criteria are stability and continuity, based on the premise that a clear definition of procedures promotes stability. Thus, as monitors, managers should know what happens in their units and check if people comply with the rules while, as coordinators, they should give emphasis to the organization and coordination of the team's efforts. ${ }^{[9,12]}$

In this model, an effective leader is one who can play the eight leadership roles simultaneously, thus facing paradox, contradiction and complexity, which characterizes health organizations. ${ }^{[13]}$ This problem is considered to be amplified in health structures given the need to lead professionals who belong to major operational development structures and structures with great technical-scientific differentiation, where most of the decision-making processes are concentrated. For this reason, the assessment of leadership roles is crucial. ${ }^{[14]}$

\subsection{Supervision satisfaction}

Supervision in nursing is fundamental and essential, since it promotes quality practices, helps and supports professionals, promoting the clients' safety. ${ }^{[15]}$

Published by Sciedu Press
Since the clinical supervision in nursing is based on the professional relationship between the nurse and the head nurse it is of utmost importance that nurses feel satisfied with the leadership.

Studies show several consequences of dissatisfaction with the supervision being the turnover the most obvious consequence. Nurses with low supervision satisfaction changed service to avoid working with their head nurses. ${ }^{[4,16]}$

Studies show that nurses value the communication, involvement, relationship and feedback from their leaders. ${ }^{[11]}$

\section{Methods}

In order to meet the research objectives, a descriptive, correlational and transversal study was conducted in a sample of staff nurses belonging to two health institutions in the district of Coimbra, in Portugal, using a questionnaire composed of 3 parts: (1) demographic data characterizing the nursing professionals, (2) Munson's Supervision Satisfaction Scale adapted by Loureiro, ${ }^{[16]}$ and (3) Quinn's Leadership Scale adapted by Parreira et al. ${ }^{[1]]}$

The Supervision Satisfaction Scale is a Likert type scale, going from 1 to 6 , from "totally disagree" to "totally agree". It has 23 statements. For each statement, the nurses mark an item which has a numerical correspondence, based on their opinion. The sum of the numerical value of the 23 items provides the final score, being a global measure. The final score can oscillate between 23 (minimum) and 138 (maximum), and the interpretation categories are: 23 to 46 very low level; 47 to 69 low level; 70 to 92 moderate level; 93 to 115 high level; and 116 to 138 , a very high level of satisfaction. Results lower than 70 show that the supervision process should be considered for an intervention to prevent a significant disruption of the process. ${ }^{[16]}$

The perception of leadership was assessed using Quinn's Leadership Model ${ }^{[9]}$ adapted to health. ${ }^{[17]}$ This instrument is a 7-point Likert-type scale (ranging from almost never to almost always). It is composed of 32 questions that assess leadership skills, distributed by 8 roles, namely: mentor, facilitator, broker, innovator, monitor, coordinator, director, and producer. These eight roles fall under the two key dimensions of leadership (flexibility/stability and external/internal guidance), from which the four leadership models are created. The human relations model is represented by the roles of mentor and facilitator; the open systems model by the roles of broker and innovator; the internal processes model by the roles of monitor and coordinator; and the rational goals model by the roles of producer and director. This instrument allows to assess the subordinates' perception of what "is characteristic" and what "should be characteristic" 
of the leader, and the gap between what is perceived and what is expected. ${ }^{[10,11]}$

The proper authorizations to apply these questionnaires were requested from the boards of the selected health institutions, as well as from the authors of the scales used in this research.

Some exclusion criteria was established: all nurses who were off duty at the time of answering the questionnaire; head nurses and nurses who work in a certain service for less than a year because one year is the legal minimum time required to assess performance evaluation.

The questionnaires were handed to 79 staff nurses and were collected in the same sealed envelope to ensure anonymity and confidentiality of the data. The data collection period was two weeks and the response rate was $88.76 \%$.

\section{RESUlts}

The Cronbach's alpha for the total 32 items of the Quinn's Leadership Model was .98. The coefficient obtained for the role of broker was .878 , for the role of monitor was .833 , for the role of coordinator was .821 , for the role of director was .825 , for the role of facilitator was .945 , for the role of mentor was .957 , for the role of producer was .936 and for the role of innovator was .917 .

The value of Cronbach's alpha for the 23 items of the Munson's Supervision Satisfaction Scale after deletion of specific items ranged from .972 to .976 . The Cronbach's alpha for the total items was .975 .

By analyzing the personal characteristics of the 79 nurses, we verified that $29.1 \%$ of the nurses of this sample were male, while $70.9 \%$ were female. The average age of respondents was 36.37 years with a median of 37 years, a minimum age of 23 years and maximum age being 58 .

In relation to the professional category, $32.9 \%$ of respondents held the professional category of "nurse", 52.2\% were "graduate nurses", and $13.9 \%$ were "specialist nurses", with a mean of 13.2 years in the profession, a standard deviation of 8.6 and a median of 15 years. Regarding the "period of time in the current service", the nurses in our sample presented a median of 4 years and a mean of 4.3 years, with a standard deviation of 3.5 years and a mode of 4 years, the minimum time being 1 year and the maximum 22 years.

Concerning the type of employment bond, $73.4 \%$ of the respondents had individual employment contracts with indefinite duration, while $26,2 \%$ had a service contract.

Regarding the type of schedule, $83,5 \%$ of the nurses had a rollman schedule (shifts), while $16.5 \%$ had a fixed schedule,
$43.0 \%$ of the nurses referred to having assumed management responsibilities or being a head nurse during their professional career, while $57.0 \%$ referred to never having assumed these roles.

In relation to staff nurses' supervision satisfaction, the lowest score was 41 , corresponding to a very low level of satisfaction; on the other hand, the maximum score was 138 , a very high level of satisfaction. The average score was 96.20, a high level of satisfaction. Thus, $3.8 \%$ of the sample presents a very low level of satisfaction, $12.7 \%$ a low level, $22.7 \%$ a moderate level, $41.8 \%$ a high level and $19.0 \%$ a very high level of satisfaction (see Table 1).

Table 1. Result of level staff nurses' supervision satisfaction

\begin{tabular}{lll}
\hline Level of supervision satisfaction & $\mathbf{n}$ & $\mathbf{\%}$ \\
\hline Very low & 3 & 3.8 \\
Low & 10 & 12.7 \\
Moderate & 18 & 22.7 \\
High & 33 & 41.8 \\
Very high & 15 & 19.0 \\
\hline
\end{tabular}

In relation to leadership perception, Table 2 shows the scores obtained regarding the staff nurse' perception of what "is characteristic" and what "should be characteristic" of the leader and the gap between what is perceived and what is expected.

Table 2 shows that all leadership roles perceived by nurses as "characteristic" presented mean scores above 4.31, and that the roles of producer (4.73), coordinator (4.65) and director (4.64) presented the highest mean scores. The role of innovator was the one least perceived (4.16). The minimum and maximum scores of the perception of "characteristic" leadership roles in the leader ranged between 1 and 4.73 .

Regarding the perception of what "should be characteristic" of a leader, we observed that the minimum and maximum values ranged between 3.50 and 7 . The expectations of subordinate nurses emphasized the role of facilitator (6.35).

The gap between the actual and the expected perceptions of leadership showed lower mean scores in the role of broker (1.40) and higher mean scores in the role of facilitator (2.09).

Pearson's correlation coefficient was calculated to examine the relationship between the leadership roles and staff nurses' supervision satisfaction. There was a positive correlation between all leadership roles and staff nurses' supervision satisfaction. All roles presented moderate correlation except the roles of facilitator $(r=.842 ; p<.001)$ and mentor $(r=.871 ; p<.001$ ), which showed a strong correlation (see Table 3). 
Table 2. Minimum, maximum, mean and standard deviation of the perception of leadership roles and the gap between what "is characteristic" and what "should be characteristic"

\begin{tabular}{|c|c|c|c|c|c|c|c|c|c|c|c|c|c|c|c|}
\hline \multirow{2}{*}{ Leadership roles } & \multicolumn{5}{|c|}{ Is characteristic } & \multicolumn{5}{|c|}{ Should be characteristic } & \multicolumn{5}{|c|}{ Gap } \\
\hline & $\mathbf{n}$ & Min & Max & Mean & $S D$ & n & Min & Max & Mean & $S D$ & n & Min & Max & Mean & $S D$ \\
\hline Role of broker & 79 & 2.00 & 6.75 & 4.58 & 1.30 & 79 & 4.25 & 7.00 & 5.98 & .72 & 79 & -1.50 & 4.25 & 1.40 & 1.22 \\
\hline Role of facilitator & 79 & 1.00 & 7.00 & 4.26 & 1.56 & 79 & 3.75 & 7.00 & 6.35 & .67 & 79 & -1.00 & 6.00 & 2.09 & 1.74 \\
\hline Role of innovator & 79 & 1.25 & 6.50 & 4.16 & 1.42 & 79 & 3.75 & 7.00 & 6.10 & .68 & 79 & -1.25 & 5.00 & 1.94 & 1.46 \\
\hline Role of mentor & 79 & 1.00 & 7.00 & 4.31 & 1.69 & 79 & 4.75 & 7.00 & 6.17 & .66 & 79 & -1.50 & 5.75 & 1.86 & 1.59 \\
\hline Role of monitor & 79 & 1.75 & 6.75 & 4.55 & 1.20 & 79 & 4.25 & 7.00 & 6.03 & .74 & 79 & -0.75 & 4.75 & 1.48 & 1.21 \\
\hline Role of producer & 79 & 1.75 & 7.00 & 4.73 & 1.33 & 79 & 4.00 & 7.00 & 6.25 & .70 & 79 & -1.00 & 4.50 & 1.52 & 1.30 \\
\hline Role of coordinator & 79 & 1.50 & 7.00 & 4.65 & 1.19 & 79 & 3.50 & 7.00 & 6.15 & .73 & 79 & -1.75 & 5.50 & 1.50 & 1.33 \\
\hline Role of director & 79 & 2.25 & 7.00 & 4.64 & 1.24 & 79 & 4.25 & 7.00 & 6.19 & .67 & 79 & -1.00 & 4.25 & 1.55 & 1.22 \\
\hline
\end{tabular}

Table 3. Relationship between staff nurse' supervision satisfaction and leadership roles

\begin{tabular}{lll}
\hline \multirow{2}{*}{ Leadership roles } & \multicolumn{2}{l}{ Supervision satisfaction } \\
\cline { 2 - 3 } & $\boldsymbol{r}$ & $\boldsymbol{p}$ \\
\hline Role of broker & .770 & $<.001$ \\
Role of coordinator & .772 & $<.001$ \\
Role of director & .764 & $<.001$ \\
Role of facilitator & .842 & $<.001$ \\
Role of innovator & .786 & $<.001$ \\
Role of mentor & .871 & $<.001$ \\
Role of monitor & .727 & $<.001$ \\
Role of producer & .779 & $<.001$ \\
\hline
\end{tabular}

\section{Discussion}

An overall analysis of the leadership instrument shows that it has satisfactory psychometric properties, which indicates that it is appropriate to assess the eight leadership roles. Internal consistency scores higher than 0.80 were found in the theoretical factors, which shows good internal consistency of the items in each factor. ${ }^{[18]}$ They were slightly higher than those found by the author of the Scale ${ }^{[9]}$ and those found in the study conducted in the Portuguese health context. ${ }^{[17]}$

The values of Cronbach's alpha of the Munson's Supervision Satisfaction Scale were higher than 90 which shows good internal consistency of the items in each factor. The reliability and validation of the survey scales showed adequate psychometric properties.

In this study, most nurses (70.9\%) were female, thus reflecting the historical trend of the profession in terms of care practice which associates it to women since the middle ages to the present time. ${ }^{[19]}$ The respondents' mean age was 36.37 years, with a standard deviation of 8.59 and a mode of 33 years. This group of nurses had a discrepancy of ages (from 23 to 58 years) that may contribute to balancing the teams.

In relation to the perception of leadership, all leadership roles perceived by nurses as "characteristic" revealed mean scores

Published by Sciedu Press above the midpoint of the scale. The roles of producer, director and coordinator showed the highest mean scores. On the contrary, the role of innovator and facilitator presented the lowest score, although it was still above the midpoint. This partially corroborated studies ${ }^{[10,11]}$ about the impact of leadership on the effectiveness of hospital organization. These studies showed a high level of skills, with greater emphasis on the performance of the roles of producer, director and coordinator.

Evidences point to a predominance of the rational goals model, since the roles of director and producer are the ones that present higher averages, corroborating other studies. ${ }^{[1,17]}$ The nurse that performs these roles possesses, as main competences, productivity and personal motivation, capability to motivate others, time and stress management, setting goals and effective delegation. ${ }^{[11]}$

Results show a tendency towards outsourcing, reflecting the importance of external environment of the organization, emphasizing the welfare and development of the organization as a whole and their relations with the outside world rather than focusing on the welfare and development of their employees. On the other hand, there is a tendency of leadership for the roles related to control and stability, instead of roles related to flexibility and change. This research identified a predominance of the tendency of manager nurses to focus on leadership roles related to the rational goals model as well as a tendency for control and external organization.

The internal processes model, which integrates the roles of monitor and coordinator, is also valued, suggesting that nurses acknowledge their head nurses as a hierarchy culture, based on rules and formal policies. This fact leads us to agree with Melo who states that health professionals feel the "need for the creation of rules and procedures that facilitate the development of projects, with a careful and empathic guidance". ${ }^{[10,11]}$ Silva adds that they feel the need of a stable and predictable environment where the guidelines and 
procedures are uniform. ${ }^{[20]}$

The leadership role that was least acknowledged by the nurses was the innovator. These low results are common to several studies, ${ }^{[11,17,21]}$ in hospital management as well as in business. The fear of moving towards the unknown is still very present in our managers, the difficulty to get out of the comfort zone persists. Domingos states that current management in Portugal restricts many of the objectives by resisting major changes. ${ }^{[21]}$ According to this author, some innovative ideas are emerging in either area, but always conducted from a stable and secure perspective, in other words, as our results confirm, there is some difficulty in the performance of leadership roles, based on flexibility. Mintzberg corroborates this fact by referring that hospitals maintain professional bureaucracies emphasizing planning and rules, instead of focusing on innovation and creativity. ${ }^{[22]}$

Thus, it is imperative to have a balance in the performance of leadership roles in order to promote the hospitals' innovation and creativity, since the leader who interprets all roles within a conscious balance, will obtain higher performance levels, regardless of the nature, the size of the company or level of competitive environment. ${ }^{[9]}$

As for the perception of what "should be characteristic" of a leader, mean scores above 6 were found, indicating a high level of demand from staff nurses. Despite this, some more modest perceptions with minimum mean scores of 3.50 were also found. The expectations of staff nurses emphasized the roles of producer and facilitator. These results may highlight the need felt by nurses to have a leader who promotes new projects, through careful and empathic guidance, associated with the effective management of such projects, and a leader who is also a facilitator, thus promoting cohesion and team work, and contributing to conflict resolution. These data highlighted the contrasting and paradoxical nature of leadership since these roles are constantly opposed. ${ }^{[23]}$

The gap obtained between the perception of the performance of leadership roles "is characteristic" and "should be characteristic" was superior in flexibility. However, the highest scores were for the human relations model, which indicates a greater need for leaders with a capability to manage conflicts, create cohesion among team members, interpersonal communication and development of their subordinates. Thus, it is necessary for the leader to acquire behaviors within the flexibility dimension, just as Bass assessed that the leaders' main flaw is inspiring leadership, ${ }^{[21]}$ which is the formula to take leadership to the next level. However, the leaders' performance obtains higher scores when flexibility is combined with control, in other words, the combined performance of the 8 roles of leadership. ${ }^{[9]}$
Relatively to staff nurses' supervision satisfaction, results suggest a generically positive satisfaction, where $41.8 \%$ of the sample shows a high level of satisfaction and $19.0 \%$ a very high level. $16.5 \%$ of the nurses are dissatisfied, since $3.8 \%$ present a very low level and $12.7 \%$ a low level of satisfaction. Loureiro considers that when low levels of satisfaction are detected, measures should be taken in order to prevent significant ruptures in the supervision process. ${ }^{[16]}$

The low levels of satisfaction (16.5\%) may suggest that the nurses do not acknowledge their head nurses' competences in the supervision process, since Quaquebeke et al. refer to the fact that subordinates do not acknowledge their leaders competence, being a source of dissatisfaction. ${ }^{[24]}$ Watson adds that satisfaction with immediate superiors is the most significant determinant of professional satisfaction and employee's organizational compromise. ${ }^{[7]}$

Regarding the relation between the leadership roles and staff nurses' supervision satisfaction, results point to a significantly positive relation for all leadership roles, indicating an association between a higher perception of nurses about the head nurses' performance in leadership roles and a higher level of supervision satisfaction. This fact can possibly be explained by the nurses' high level of demand, for the perception of "what should be typical" for all roles, suggesting that nurses acknowledge that the performance of every role is fundamental for an effective leadership process, which is corroborated by Quinn and Rohrbaugh, who claim that a leader who has all the roles, will acquire higher levels of performance, regardless the nature, size of the company or the level of competitive environment. ${ }^{[9]}$ Melo also refers that those effective leaders "are perceived as having a simultaneous development of all leadership roles". [10,11]

The roles of facilitator and mentor present a higher correlation, confirming the expectations of the nurses with a tendency towards the human relations model.

\section{Conclusion}

This study noticed a tendency of the performance of head nurses in leadership roles within the rational goals model, indicating a higher concern with planning, defining goals, productivity and efficiency. An emphasis on outsourcing was also evident, emphasizing the importance of the external environment of the organization. On the other hand, the inclination towards control is notorious, reflecting the tendency for the performance of roles related to control and efficiency, instead of roles related to flexibility and change.

The low perception of the performance of the innovator role, demonstrates the persisting difficulty of Portuguese managers to leave comfort zones, particularly, head nurses, suggesting 
the need for training.

Nurses are overall satisfied with supervision; however, $16.5 \%$ of the sample is dissatisfied, indicating that measures should be taken to prevent significant ruptures in the supervision process.

This study enabled us to corroborate other results obtained by other investigators concerning supervision satisfaction according to professional variables, namely having a fixed schedule. This can be explained by the fact that the nurses who have a fixed schedule spend more time with their head nurse, giving them the opportunity to establish a more trusting relationship, so we suggest developing strategies that allow them to spend more time with the entire team, as a way to optimize their relationships and improve the nurses' supervision satisfaction.
A positive relation between the performance of all leadership roles and supervision with satisfaction was observed, which allows us to conclude that the leader who performs all leadership roles, besides increasing their levels of effectiveness and efficiency, also increases the level of staff nurses' supervision satisfaction.

However, we need to be careful while interpreting these results because of the limitations presented by this research, such as its small sample of nurses and low geographical coverage. Thus, we suggest using a larger sample as to cover a wider geographical area to increase representativeness in future research opportunities. We also suggest carrying out studies to assess the organizational consequences of dissatisfaction with the supervision in order to be able to take corrective measures.

\section{REFERENCES}

[1] Ordem Dos Enfermeiros. As condições de trabalho dos enfermeiros Portugueses. Lisboa: OE; 2004.

[2] Drucker Peter F. The effective executive. New York: Collins; 2006. PMid: 16485812.

[3] Jesuíno J. Processos de liderança. Lisboa: Livros Horizonte; 2005.

[4] Menezes M. Liderança e satisfação profissional em enfermagem [dissertation]. [Vila Real]: Universidade de Trás-os-Montes e Alto Douro; 2010.

[5] Cunha M, Rego A, Cunha RC, et al. Manual de comportamento organizacional e gestão. $6^{a}$ ed. Lisboa: Editora RH; 2007.

[6] Cohen A, Fink S. Comportamento organizacional: conceitos e estudos de caso. Rio de Janeiro: Editora Campus; 2003.

[7] Watson L. Leadership's influence on job satisfaction. Radiologic Technology. 2009; 4(80): 297-308.

[8] Santos A. Gestão estratégica: conceitos, modelos e instrumentos. Lisboa: Escolar Editora; 2008.

[9] Quinn R, Rohrbaugh J. A spatial model of effectiveness criteria: towards a competing values approach to organizational analysis. Management Science. 1983; 3(29): 363-377. http://dx.doi .org/10. $1287 / \mathrm{mnsc} .29 .3 .363$

[10] Melo R, Parreira P, Silva MJ. Leadership and management in the development of relational skills in nurses: a systematic review of literature. Procedings of International Conference on Complexity in Leadership and Management. IPM Pvt. Ltd., Interscience Campus, Índia. 2011; 32-37.

[11] Melo R. Liderança e gestão: desenvolvimento de competências relacionais. Lusodidacta: Loures. 2014.

[12] Quinn RE. Beyond Rational Management: Mastering the Paradoxes and Competing Demands of High Performance. San Francisco: Jossey-Bass Inc. Publishers. 1988.

[13] Deninson DR, Hooijberg R, Quinn R. Paradox and performance: Toward a Theory of behavioural complexity in managerial leadership.
Organization Science. 1995; 6 (5): 524-540. http://dx.doi.org /10.1287/orsc.6.5.524

[14] Melo R, Silva M, Parreira P. Effective leadership: Competing Values Framework. Procedia Technology. 2014; 16: 921-928. http: //dx.doi.org/10.1016/j.protcy. 2014.10.044

[15] Bond M, Holland S. Skills of clinical supervision for nurses. Buckingham: Open University Press; 1998.

[16] Loureiro R. Liderança em enfermagem: satisfação dos enfermeiros Segundo o tipo de liderança da chefia [dissertation]. [Lisboa]: Instituto Superior de Ciências do Trabalho e da empresa, Lisboa, Portugal

[17] Parreira PM, Felício MJ, Lopes A, et al. Papéis de liderança: Um instrumento avaliativo. Revista de investigação em enfermagem. 2006; 13: 3-14.

[18] Hill MM, Hill A. Investigação por questionário. Lisboa: Edições Silabo; 2008.

[19] Collière M. Promover a vida: da prática das mulheres de virtude aos cuidados de enfermagem. $3^{a}$ ed. [Lisboa]: Sindicato dos Enfermeiros Portugueses. 1989.

[20] Silva M. Avaliação de competências de liderança nos líderes intermédios: desempenho/eficácia organizacional [dissertation]. [Coimbra]: Faculdade de Economia da Universidade de Coimbra; 2010.

[21] Domingos M. Gestão da cultura pelas chefias intermédias. Estudo de caso de uma entidade pública empresarial - OPART [dissertation] [Lisboa]: ISCTE, Instituto Universitário de Lisboa; 2009.

[22] Mintzberg H. Tracking strategies: Toward a general theory of strategy formation. New York: Oxford University Press; 2009.

[23] Quinn RE. Beyond Rational Management: Mastering the Paradoxes and Competing Demands of High Performance. San Francisco: Jossey-Bass Inc. Publishers; 1988.

[24] Quaquebeke N, Kerschreiter R, Buxton AE, et al. Two lighthouses to navigate: effects of ideal and counter-ideal values on follower identification and satisfaction with leaders. Journal of Business Ethics. 2010; 93: 293-305. http://dx.doi.org/10.1007/s10551-009 $-0222-\mathrm{x}$ 